\title{
Cutaneous Melanoma pTO TNM Finding v8
}

National Cancer Institute

\section{Source}

National Cancer Institute. Cutaneous Melanoma pT O TNM Finding v8. NCI Thesaurus. Code C136939.

Cutaneous melanoma with no evidence of primary tumor (e.g., unknown primary or completely regressed melanoma). Thickness: Not applicable. Ulceration status: Not applicable. (from AJCC 8th Ed.) 